\title{
Gender differences in self care in type 2 diabetes in rural Kerala
}

Morris $\mathrm{MC}^{1 *}$, John $\mathrm{MS}^{2}$

*Corresponding author:

${ }^{1}$ Dr. Maria Cheryl Morris, B.D.S, M.P.H, Ph.D. Assistant Professor, Centre for Professional and Advanced Studies, School of Medical Education, Kottayam, Kerala.

Email: drsherryaby@gmail.com $\underline{\text { ORCID }}$

${ }^{2}$ Professor \& Head of the Department, Dean, School of Global Studies, Central University of Kerala, Kasargod, Kerala, India

\section{Information about the article:}

Received: Jan. 17, 2019

Accepted: Feb. 20, 2019

Published online: Dec. 27, 2019

\section{Publisher}

Nepal Health Research Society, Bahundhara -6,
Gokarnesowor Municipality, Kathmandu, Nepal

eISSN 2382-5545, ISSN 2676-1343 (Print)

(c) The Author(s). 2019

Content licensing: CC BY 4.0

\section{ABSTRACT \\ Background}

Noncommunicable Diseases (NCDs) were estimated to have contributed to almost $60 \%$ of deaths in the world and $43 \%$ of the global burden of disease in 1999. NCDs are rapidly becoming a major public health threat in the developing world. The W.H.O fact file on NCDs states that healthy diet, regular physical activity, maintaining a normal body weight (self-care) are ways to prevent or delay the onset of type 2 diabetes or its complications. Thus, self-care in diabetes is the corner stone in achieving good glycemic control, thereby preventing the onset of diabetes complications which increases the morbidity and mortality of the disease. This study was undertaken to understand the effect of self-care on HbA1C (blood sugar control) among males and females with Type -2 diabetes in a rural population in Kerala. The study tries to draw out the differences in self-care among males and females taking into consideration the patriarchal nature of the society and to understand the gender differences in approaches to self-care. Sex- based differences should be considered when developing awareness and treatment programs for people with diabetes, more precisely in NCD preventive measures specifically for the Indian subcontinent.

\section{Materials and methods}

A cross sectional study was conducted in a stratified random sample of diabetes patients belonging to the three religious groups found in the study area, in a diabetes treatment center in Kanjirapally taluk of Kottayam district. Based on pilot study, a sample of 300 is chosen with 138 males and 162 females. For part 1 of the questionnaire, demographic details were entered by the researcher and the medical records were accessed to record the relevant details like height, weight, A1C, B.M.I., F.B.S. and chronic conditions of the patients. The selfcare activity of the patients were assessed with the SDSCAS (Summary of diabetes self-care activity scale). It consists a core set of 12 questions to assess the dietary habits, exercise regimen, blood sugar testing, foot care and smoking status for the past 7 days.

\section{Results}

Since the representative sample is not made of equal number of males and females, comparison of blood sugar control (HbA1C) based on self-care activities for males and females were calculated. The independent sample t-test is highly significant at 0.01 level with respect to general diet, specific diet, dietary adherence and podiatric care. The t-test again shows significance at 0.05 level with respect to physical activities on comparison.

\section{Conclusions}

The self-care activities varied greatly between males and females. The self-care activities of the females were very poor when compared with the males. The poor self-care activities of the females could be attributed to behaviour conditioned by gender relations prevalent in the society. Women seem to assimilate or internalize the patriarchal subjectivity of the society. But this is a feature of most households not only in the study area but of the country as a whole. This gender difference in self-care can be annihilated by stringent awareness and health education campaigns. NCD prevention strategies should include gender sensitive health promotion measures to achieve the WHO Global Strategy for the Prevention and Control of Noncommunicable Diseases (NCD Action Plan).

Key words:

Diabetes, gender differences, Kerala, non communicable disease (NCD), self-care. 